being near and around the cricoid lamina. The source of infection was probably in the left tonsil, which was swollen and had led to the secondary swelling of the left submaxillary gland.

\section{Review of Literature}

Koerner (1914) regards dyspnoea and pain on swallowing as the principal and most frequent complaint in laryngeal perichondritis. Denker and Bruenings (1921) state that temperature and distressing pain usually appear in the course of acute laryngeal perichondritis, lancinating into the ears when swallowing. I have stated (Rosenbaum, 1930) that pain in swallowing, earache, and tenderness on palpation are always present; also shortness of breath, but this last remark is certainly wrong. Dyspnoea can be, but is not necessarily, present. Wessely (1944) proposed "prontosil" (sulphonamide) therapy in cases of phlegmonous laryngitis. The Chevalier Jacksons (1942) distinguish between oedematous septic laryngitis and laryngeal perichondritis, defining the former as an aggressive inflammatory condition in which the submucous and deeper tissues are involved, while regarding the latter as possibly a secondary and late development of the septic type of inflammation. They state that the oedema secondary to perichondritis is pale, as compared with the intense red usually seen in septic laryngitis. They enumerate as symptoms of phlegmonous laryngitis, hoarseness, some fever, complete aphagia, offensive breath, and croupy voice in cases of subglottic involvement. These authors give a general picture of acute perichondritis as that of an acute watery or acute red oedema. The Jacksons (1945) also declare that the colour of the swollen tissue in perichondritis varies. That is also my opinion. Simultaneous changes occur in the character of the disease, the colour of the oedema and inflammation, and in the symptoms; but the colour of the oedema should be of no great importance to the practitioner.

\section{Summary and Conclusion}

Eight cases (three males and five females) of phlegmonous laryngitis were observed in the course of three and a half years. Israel is a very small country and far more cases of this kind might be expected amongst larger communities. If the cases come within a general practitioner's observation and are not cared for properly at the very beginning the results may be disastrous. I would suggest that the disease be called "laryngeal cellulitis" or " phlegmonous laryngitis." Laryngeal perichondritis may be a sequel, and a rapid invasion through an almost unharmed mucosa may result in a very early perichondritis without the expected preceding laryngeal cellulitis. Severe pain on swallowing, when accompanied by grimacing and earache, may be caused by some deep-seated condition of the larynx. Aural pains were present in all my cases. No "septic mouth" or offensive breath was observed. Two of the patients had had their tonsils removed some years previously. In one case an overlooked maxillary sinusitis might have been the cause of the laryngeal infection. Hoarseness was observed in two cases. Overflow of mucus into the larynx caused cough in two cases, but did not appear as a significant diagnostic sign. Dyspnoea was not observed in any of the cases.

After the physician has considered the symptoms, palpation of the larynx should be the next step. If digital exploration reveals local tenderness, glands, or swellings, deep laryngeal infection may be suspected. Five of my cases showed external tenderness; the others did not. Therefore external palpation may lead one astray. The final diagnosis is dependent on mirror examination. Once the physician has the knack of handling the laryngeal mirror he will be able to observe in the reflected image the changes due to the use of modern drugs.
Five of my cases improved in one day after chlortetracycline had been given; one case needed a total of $2 \mathrm{~g}$., the others needed doses of from 2.5 to $4.75 \mathrm{~g}$. The use of chloramphenicol in one case, together with a small amount of chlortetracycline, seemed less effective. Penicillin alone was given in Case 1 and Case 8, in the latter because the diagnosis was uncertain; I believe the six-day treatment could have been shortened with chlortetracycline. Case 1 responded quickly to penicillin although this patient was in quite a serious condition. She was cured within four days with only $2,400,000$ units. Three other cases did not respond satisfactorily to penicillin injections of between $1,200,000$ and $4,400,000$ units, but treatment in these cases was continued successfully with chlortetracycline.

It may be concluded that violent submucous invasion of the connective tissue and the deeper layers of the larynx result in an oedema of the various cartilaginous parts. Although symptoms may point towards the right diagnosis, mirror inspection of the larynx is absolutely urgent. Once diagnosis has been established, chlortetracycline in doses of $250 \mathrm{mg}$. six-hourly appears to be the treatment of choice.

REFERENCES

Denker, A., and Bruenings, W. (1921). Lehrbuch der Krankheiten des Ohres und der oberen Luftwege, 7 Aufl., p. 550. Fischer, Jena. ckson, Chevalier, and Jackson. Chevalier L. (1942). Diseases and Injuries of the Larynx, 2nd ed., p. 134. Macmillan, New York.

(1945). Diseases of the Nose, Throat and Ear, p. 471. Saunders, Philadelphia and London.

Koerner, O. (1914). Lehrbuch der Ohren-, Nasen- und Kehlkopfkrankheiten, 5 Aufl., p. 194. Bergmann, Wiesbaden.

Rosenbaum, E. (1930). Obere Luftwege, obere Speisewege, Ohr, p. 66. Enslin, Berlin

Wessely, E. (1944). Klinik der Hals-, Nasen- und Ohrenerkrankungen, p. 261. Urban and Schwarzenberg, Berlin.

\section{ANAEMIA OF NEWBORN FOLLOWING ANTERIOR PLACENTA PRAEVIA} BY

N. R. BUTLER, M.D., M.R.C.P., D.C.H.

First Assistant, Children's Department, University College Hospital

AND

J. D. MARTIN, M.D., M.R.C.O.G.

Late Assistant to the Obstetric Unit, University College Hospital

Foetal anaemia following incision of the placenta in caesarean section has been recognized for over 70 years. Leopold (1888) stated: "I warn against the practice of cutting through the placenta at caesarean section or boring through it with the finger. It results in considerable loss of blood and endangers the life of the child. ... It is better to insert the hand between the uterine walls and the placenta, push the latter aside, rupture the membrane and grasp the child by the nearest limb." Kelly (1891), after performing his first four classical caesarean sections, stated: "The placenta should not be incised for fear of bleeding the infant." Siddall and West (1952) reviewed 65 babies delivered by classical or lowersegment caesarean section, in all of whom they carried out haemoglobin and red blood counts. All but one of the seven anaemic babies in their series had been delivered by the lower-segment operation, which was carried out for placenta praevia in three instances. In another five of their series the placenta was incised, with no foetal anaemia. 
Since the lower-segment approach has become standard practice in caesarean section, incision of the placenta is relatively uncommon, except in cases of anterior placenta praevia. The danger of post-haemorrhagic anaemia after incision of the placenta is stressed by the following five cases, which have been recorded out of a total of 19 lower-segment caesarean sections carried out for placenta praevia in one obstetric hospital (U.C.H.) during the years 1949-52 inclusive.

\section{Case Reports}

Case 1.-A 35-year-old Rh-positive multigravida was found to have positive Wassermann and Kahn reactions when three months pregnant, following which a six-days course of intramuscular penicillin was given. She was admitted from the district three weeks after term following a slight ante-partum haemorrhage which increased early in labour. A vasa praevia was suspected on examination under anaesthesia, but lower-segment caesarean section revealed an anterior-lying Type II placenta praevia. The placenta was incised during the operation. The baby, a male weighing 2,800 g. (6 lb. $2 \frac{3}{4}$ oz.), was limp and pale at birth and breathed only after resuscitation with intranasal and intragastric oxygen. A direct Coombs test was negative on the cord blood, as was the Wassermann reaction. The cord haemoglobin level was $13.3 \mathrm{~g}$. ( $90 \%$ Haldane), falling to 10.9 g. ( $74 \%$ Haldane) on the seventh day, when a blood transfusion of $72 \mathrm{ml}$. was given. The baby was well on discharge from hospital on the 16th day and subsequently showed no clinical evidence of congenital syphilis, with a negative Wassermann reaction at three months.

Case 2.-A 26-year-old Rh-positive primigravida was admitted after a slight ante-partum haemorrhage at 39 weeks, when examination under anaesthesia revealed a Type IV placenta praevia. The placenta was incised during lowersegment caesarean section. The baby was a female weighing $3,005 \mathrm{~g}$. (6 lb. $10 \mathrm{oz}$.). There was pallor and poor tone at birth, and onset of respiration was delayed for several minutes. The peripheral haemoglobin at the age of six hours was $13.3 \mathrm{~g}$. (90\% Haldane) and $10.9 \mathrm{~g}$. (74\% Haldane) on the 13th day. In spite of treatment with iron, the red count was only $3,000,000$ and haemoglobin $8.8 \mathrm{~g}$. $(60 \%$ Haldane) at the age of 6 weeks, followed by gradual spontaneous rise to a normal level.

Case 3.-A 36-year-old Rh-positive multigravida was admitted following ante-partum haemorrhage at 33 weeks, recurring more heavily at 34 weeks. A Type III placenta praevia was diagnosed under anaesthesia and a lowersegment caesarean section was carried out, in the course of which an incision was made in the placenta. The infant, a female weighing 1,772 g. ( $3 \mathrm{lb}$. $14 \frac{1}{2} \mathrm{oz}$.), was pale and limp at birth, but breathed at once. The peripheral haemoglobin level at 18 hours was $13.3 \mathrm{~g}$. (90\% Haldane). The baby remained well apart from a residual anaemia, with a haemoglobin of $8.4 \mathrm{~g}$. (57\% Haldane) at the age of 1 month, following which spontaneous improvement occurred.

Case 4.-A 35-year-old Rh-negative multigravida developed moderate ante-partum haemorrhage at 30 weeks. A further haemorrhage occurred at 32 weeks, when examination under anaesthesia showed a Type III anteriorly placed placenta praevia. The placenta was cut during lowersegment caesarean section, which was carried out for continued haemorrhage. The infant, a premature male weighing $1,928 \mathrm{~g}$. (4 lb. $4 \mathrm{oz}$.), was limp and pale at birth, with delayed onset of respiration for several minutes. The peripheral haemoglobin at 1 hour was 15.1 g. (102\% Haidane), falling at 36 hours to $10.2 \mathrm{~g}$. (69\% Haldane). There was persistent respiratory difficulty in spite of treatment in oxygen with high humidity. At 40 hours a transfusion of $45 \mathrm{ml}$. of Rh-negative compatible packed cells was given into the left saphenous vein, but the baby died one hour later. Necropsy showed marked pallor of the viscera, together with a hyaline-like membrane in the lungs.
Case 5.-A 27-year-old Rh-negative primigravida was admitted for ante-partum haemorrhage at 41 weeks. Examination under anaesthesia revealed a Type II anterior placenta praevia. At lower-segment caesarean section the placenta was incised and the foetal head was found to be obstructed by a band of placental tissue, which was divided with scissors. During this manipulation two large placental vessels were cut close to the insertion of the cord. The baby was a female weighing $3,856 \mathrm{~g}$. ( $8 \mathrm{lb} .8 \mathrm{oz}$.), pale and limp at birth, but breathing spontaneously at once. The cord haemoglobin level was 16.3 g. ( $110 \%$ Haldane), but this comparatively normal figure was almost certainly due to lack of haemodilution, as the baby appeared pale and exsanguinated 30 minutes after delivery. A direct Coombs test on the infant's cord blood was negative. An emergency transfusion of $150 \mathrm{ml}$. of $\mathrm{Rh}$-negative group $\mathrm{O}$ blood was given into the umbilical vein in the first hour of life, with immediate improvement in the baby's condition. The peripheral haemoglobin level at 24 hours was 18.3 g. (130\% Haldane) and the baby was very well on discharge from hospital on the 14th day.

\section{Discussion}

The haemoglobin levels in Cases 1-4 were all below the range of normal values quoted by Mollison (1951), who found a normal cord haemoglobin range of between 13.5 and $19.6 \mathrm{~g}$. (91-132\% Haldane) and a normal peripheral haemoglobin level in the first 24 hours of 15.4-22.8 g. (104$154 \%$ Haldane). In Case 5 the haemoglobin level was undoubtedly misleading owing to the lack of haemodilution. This case was clinically the most severely affected in the series, and illustrates that post-haemorrhagic anaemia of the newborn can be an acute emergency requiring immediate replacement of blood, which in this case was life-saving. Transfusion was delayed in Case 4 until the infant was 36 hours of age, as he was severely ill with respiratory embarrassment, confirmed at necropsy to be due to a hyalinelike membrane in the lungs. Case 1 was transfused at the age of 7 days, and in Cases 2 and 3 early transfusion might have been advantageous in view of the persistence of anaemia at the age of 1 month.

Exsanguination of the newborn may follow a number of abnormalities of placenta and umbilical cord apart from placenta praevia. Wickster (1952), in addition to commenting on the danger of foetal haemorrhage from the vasa praevia, also stressed this complication in velamentous insertion of the cord and abruptio placentae. He described six cases of newborn post-haemorrhagic anaemia, five of which were fatal. In order to explain the foetal anaemia which occurred in one of his cases with normal placenta and vessels with a spontaneous delivery, he suggested that foetal haemorrhage might occur towards the end of labour from extravasation of foetal blood into the decidual space at the uteroplacental junction. Further, Wiener (1948) believed that foetal blood loss may occur into the maternal circulation during pregnancy through a defect on the foetal side of the placenta. In order to determine whether foetal haemorrhage occurred after caesarean section for conditions other than placenta praevia, or in any cases of placenta praevia not delivered by caesarean section, the records of the remaining 235 caesarean sections carried out for other indications were studied, as were those of the seven cases of placenta praevia delivered per vias naturales. No anaemic babies were recorded in either group. Study of the full operative details available in 7 of the 14 non-anaemic babies delivered by lower-segment caesarean section for placenta praevia showed that in two of these the placenta had been incised without any blood loss in the infant.

For caesarean section in cases of placenta praevia, the majority of writers favour the lower-segment approach Marshall (1939) found the placenta involved in the incision or manipulation in $14(30 \%)$ of his cases. He did not mention any possible danger to the infant, and considered disturbing or detaching the placenta during the operation to be of no consequence; on two occasions he actually removed the placenta first. Macafee (1945), in advocating the 
conservative treatment of placenta praevia, stated: "At the lower segment operation the cord may be cut through or pulled off, causing anaemia in the child." He quoted two such cases, one of which was very similar to Case 5 , in which large placental vessels on the foetal surface were incised very close to the insertion of the cord. To avoid the danger of bleeding from the child Macafee recommended a stab incision into the lower segment and careful stretching of the incision with the fingers, thus avoiding damage to the placenta. This seems the best approach in the majority of cases, although it may often be equally effective to make the incision in the uterine wall a little higher than usual. If palpation suggests that injury to the placenta is inevitable or if, as sometimes happens, the lower segment is poorly formed, the classical approach may be justified in the interests of the child, but on no account should the placenta be removed before the child.

The differential diagnosis of the clinical picture following foetal haemorrhage is that of birth anoxia and birth trauma. Pallor and lack of tone may occur in all three conditions, but, while delayed onset of respiration is always present in birth anoxia, three out of five of the babies with posthaemorrhagic anaemia in the present series breathed spontaneously at birth. Further, babies with post-haemorrhagic anaemia remain pale, whereas normal colour returns after successful resuscitation of anoxic babies. Babies suffering from cerebral birth trauma may show other signs such as irritability, high-pitched cry, full fontanelle, increased tone in the limbs, and even convulsions. Post-haemorrhagic anaemia has also to be differentiated from haemolytic anaemia following blood-group incompatibility. Antenatal rhesus blood grouping and routine tests for agglutinins in rhesus-negative mothers will reveal in advance nearly all cases of rhesus-blood-group incompatibility, while the direct Coombs test is positive on the infant's cord blood. Posthaemorrhagic anaemia may occur shortly after birth from a slipped ligature of the umbilical cord, but the source will be evident.

In conclusion, in all cases with placenta praevia delivered by caesarean section arrangements should be made for haemoglobin determinations on the cord or infant's blood. As haemodilution may not occur for several hours after haemorrhage, serial haemoglobin estimations may be necessary after birth, taking into account that the normal haemoglobin level in the baby's peripheral blood is usually about $20 \%$ higher than the cord level. In every case preparations should be made for immediate transfusion of the child.

\section{Summary}

Five cases of post-haemorrhagic anaemia of the newborn are described following lower-segment caesarean section for placenta praevia and occurring in every case after incision of the placenta. In two other instances the placenta was incised without anaemia in the infant. In 235 caesarean sections carried out for other reasons in the same period there were no cases of anaemia in the infant; neither was the baby affected in seven cases of placenta praevia delivered by the vaginal route.

Methods for avoiding damage or incision of the placenta during delivery are discussed. The need for prompt recognition and treatment of post-haemorrhagic anaemia in the newborn is stressed.

We are indebted to Professor W. C. W. Nixon and the consultant obstetric staff of University College Hospital for their permission to publish these cases.

\section{REFERENCES}

Kelly, H. A. (1891). Amer. J. Obstet. Dis. Wom., 24, 532. Leopold, C. G. (1888). Der Kaiserschnitt, pp. 169, 27. Leipzig. Macafee, C. H. G. (1945). J. Obstet. Gynaec. Brit. Emp., 52, 313. Marshall, C. M. (1939). Caesarean Section, p. 159. Wright, Bristol. Mollison, P. L. (1951). Blood Transfusion in Clinical Medicine. Blackwell Scientific Publications.

Siddall, R. S., and West, R. H. (1952). Amer. J. Obstet. Gynec., 63, 425. Wickster, G. Z. (1952). Ibid., 63, 524

Wiener. A. S. (1948). Ibid., 56, 717 .

\section{ACIDAEMIC COMA AFTER BILATERAL TRANSPLANTATION OF GRETERS}

\author{
BY
}

\section{E. KEITH WESTLAKE, M.A., M.D., M.R.C.P. Late Medical Registrar, Chase Farm Hospital}

The frequency with which a chronic acidaemia with hyperchloraemia and raised blood urea occurs after bilateral transplantation of the ureters has been appreciated only since Ferris and Odel's (1950) review. In the last four years over 25 papers have been written on this topic, but the majority have appeared in the urological literature, and many physicians may be unaware of a characteristic clinical syndrome and its correct management. The case reported below is the first in which serial measurements of arterial blood $p \mathbf{H}$ have been made during recovery from acidaemic coma precipitated by acute pyelonephritis.

\section{Case Report}

A 66-year-old retired wood-sawyer was readmitted to Chase Farm Hospital on September 29, 1953. In October, 1949, bilateral uretero-sigmoid anastomosis and total cystectomy was performed for carcinoma of the bladder. $\mathrm{He}$ remained in moderate health but complained of easy fatigability, muscular weakness, dyspnoea on exertion, central chest pain of anginal character, increased thirst, and frequent attacks of malaise, fever, shivering, and anorexia suggestive of recurrent acute pyelitis. His weight fell from 10 st. $6 \mathrm{lb}$. to 8 st. $10 \mathrm{lb}$. ( 66.2 to $55.3 \mathrm{~kg}$.).

Two weeks before admission he developed a further attack of malaise, shivering, and headache. On September 26 he felt well enough to get up, but after walking in the garden developed central chest pain and a feeling of extreme weakness, and retired to bed. On the following day he vomited once. On the 28th he became drowsy and subsequently unrousable. No urine had been passed for twelve hours prior to admission.

On examination he was comatose, with Kussmaul breathing. $\quad$ T. $99.2^{\circ}$ F. $\left(37.3^{\circ}\right.$ C.) ; R. 9-12 ; P. 110 . There was moderate dehydration, but the extremities were warm, and blood from the antecubital vein was arterial in colour. Intermittent twitching of facial muscles, platysma, and arms occurred. B.P. 140/70 (usual level 170/105). Deep reflexes were all increased, with sustained clonus of right ankle.

Arterial blood analysis showed severe acidaemia with hyperchloraemia and raised blood urea $-p H$ 7.08; plasma $\mathrm{CO}_{2}$ content, $4.5 \mathrm{mEq}$ (10 vols.); $\mathrm{pCO}_{2}, 13 \mathrm{~mm}$.; sodium, $145 \mathrm{mEq}$; potassium, $4.3 \mathrm{mEq}$; chloride, $114 \mathrm{mEq}$; blood urea, $231 \mathrm{mg}$. per $100 \mathrm{ml}$. The acidaemia was treated by rapid infusion of $3.8 \%$ sodium citrate. After twenty to thirty minutes the level of coma lightened and extreme restlessness necessitated sedation with paraldehyde. After 1.7 litres of sodium citrate in three hours, the arterial $p \mathrm{H}$ had risen to 7.48 , but clinical hyperventilation was still present with an arterial $\mathrm{CO}_{2}$ tension reduced to $20.9 \mathrm{~mm}$. and a plasma $\mathrm{CO}_{2}$ content of $15.8 \mathrm{mEq}$. Rehydration was continued with $5 \%$ glucose and the presumed pyelonephritis treated with chlortetracycline ("aureomycin "), $500 \mathrm{mg}$. twice daily, added to the intravenous drip (total 14 g.). On October 1 he was fully conscious and replied slowly but rationally to questioning; the blood urea had risen to $297 \mathrm{mg}$. He complained of profound anorexia and lethargy, and was found to have developed moderate hypokalaemia (K $2.4 \mathrm{mEq}$ ). Potassium deficiency was repaired by the intravenous administration of a potassium phosphate solution $(60 \mathrm{mEg}$ per litre) and subsequently by potassium citrate orally.

The serum level returned to normal on the tenth day after $1,000 \mathrm{mEq}$ of potassium. Balance studies proved 